\title{
What (else) matters? Policy contexts, emotional geographies
}

\begin{abstract}
This paper reflects upon a particular, policy-oriented evaluation of a Sure Start Centre: a small element of a UK-Government programme addressing children's well-being in 'deprived' neighbourhoods. Specifically, and contra some chief social-scientific accounts, we seek to acknowledge how 'policy' and 'emotion' were inseparable in this project. We suggest that policy and media discourses, and much extant research, regarding Sure Start have been characterised by a particular apprehension of what matters, which constitutes a particular assumption about how policy interventions, in 'deprived' neighbourhoods and elsewhere, should be evaluated. In marked contrast, we propound qualitative data wherein users of the Sure Start Centre articulated how this facility mattered to them. Our aim is not simply to reiterate a twofold truism: policy is always emotional; emotions are latently political. Rather we consider how, in the wake of this truism, more combinative, open-minded encounters between bodies of socialscientific endeavours conventionally labelled 'policy-relevant' vis-à-vis 'theoretical' might yield more careful apprehensions of the emotion/affect in policy, and the politics of emotions/affects.
\end{abstract}




\section{What (else) matters? Policy contexts, emotional geographies}

\section{Preface}

We exit the Sure Start Centre ${ }^{1}$, tape recorders and notebooks in hand. A sunny day. We get in the car and sit, speechless. My co-researcher begins to weep; she hits the steering wheel, sobbing. I sit silent, numbed. For hours, days, afterwards, the story we have just heard tumbles through my head, over and again.

\section{Introduction}

This paper concerns a particular, policy-oriented research project: an evaluation of a Sure Start Centre (see below) in a town in the UK's East Midlands. Specifically, we seek to acknowledge the emotional heart - manifest in tears, numbness, deeply-affecting stories - of this project, and others like it. For it is our contention that this kind of emotion (raw, haunting, excessive) in/of this kind of project (policy-relevant, 'useful') irrevocably complicates some working assumptions which have become habitual, arguably orthodox, prompts for much social-scientific research/practice.

We begin by locating the paper in two contexts. First: in relation to recent theorisations which have variously acknowledged co(i)mplications of emotions and policy/political practices in contemporary urban contexts. But then, second: in the context of two commonplace rationales/inclinations within social-scientific research/practice which have, in our view problematically, foreclosed and circumscribed apprehension of precisely that kind of complication. We then pursue these lines of thought via a case study: the aforementioned Sure Start Centre evaluation. Our analysis contrasts extant, national-scale Sure Start policy/practice and associated evaluations with our own, local research findings regarding one Centre. We do not suggest that the latter is attuned to 'emotions' whereas the former is simply attuned to 'policy'. Rather, we suggest that in each case (national and local) there exists a more complex relationship between both 'emotions' and 'policy' - a relationship that, in each case, propounds a different but related view of 'what matters' in and for Sure Start Centres. Furthermore, we signal not only how emotions and policy are differentially co(i)mplicated in each context - but how

\footnotetext{
${ }^{1}$ We anonymise the centre as 'the Sure Start Centre' throughout this paper.
} 
'national' and 'local' kinds of mattering are also co(i)mplicated at our particular, case study Sure Start Centre.

\section{Articulations of policy and emotion}

One consequence of a gathering social-scientific apprehension of emotions and affects (Williams, 2001; Bondi et al., 2005) has been the charting of some fundamental, but toooften-effaced, connections between that field of practice conventionally known as 'policy' and that range of affective, bodily intensities conventionally named 'emotion' 2 For example, first, social and cultural geographers have begun to map ways in which iterations of local, regional and national policy-making - the closure of a coalmine, the renewal of facilities for asylum-seekers, the rationalisation of civic welfare provision, for example - invariably have quotidian, human and emotional costs and consequences, for better or worse (Anderson and Smith, 2001; Hubbard, 2005; Horton and Kraftl, forthcoming). Or, second, social-scientific accounts of activism and protest have increasingly explored the role of emotions in sparking and sustaining politicised dispositions and consciousness (Brown and Pickerill, forthcoming). In particular, the centrality of intimate, emotive, embodied experience in the constitution of both personal radicalisation and empathetic collectivities has been extensively chronicled (Williams, 2001), around, for example, gender (Smith et al., 2008), sexuality (Brown, 2007), dis/ability (Chouinard, 1997) and environmental ethics (Smith, 2005).

Elsewhere, third, meta-theoretic accounts of urban sociality have begun to apprehend emotions and affects - be they "incandescent passions" or the plainer, "constant swirl of emotions that takes us through the day" (Amin and Thrift, 2002, page 83) - as fundamental to processes and projects of policy and politics. For example, such accounts have foregrounded the targeting and (ab)use of civil bodies and affects by political technics, practices and discourses (Thrift, 2004, 2008), and the role of affects -like hope,

\footnotetext{
${ }^{2}$ Of course, neither of these conventions is given nor unproblematic, especially in the wake of recent apprehensions of the affective heart of politics and the multifarious politics of affect (see, respectively, Bessant, 2008; Anderson and Harrison, 2006). However, throughout this paper we do maintain the terms 'policy' and 'emotion', because: (a) the research described herein was exemplary, in many ways, of a kind of work which is widely and habitually described as 'policy research'; (b) the research participants quoted herein did, effectively universally, talk in terms of their 'emotions'.
} 
promise, conviction, assent - as part, parcel and product of doing policy-making (Bessant, 2008), as well as infrastructural in policies themselves (Anderson and Holden, 2008). Moreover, accounts in this context have registered the significance of particular, often subtle, quotidian affective intensities - like generosity, care, trust; or anxiety, disappointment, antagonism - in the passing constitution of events, ethics and solidarities which are, in effect (if not intent or name) politics, albeit often of a kind aside from structural normatives (Anderson and Harrison, 2006; Dewsbury, 2007). Such politics, and such intensities, can be adjudged affirmative, touching and hopeful (Laurier and Philo, 2006; Cloke et al., 2008; Kraftl 2008); equally, of course, they can be disappointing or troubling (Valentine, 2008), insidious or exclusionary (Pain, 2001; Pain and Smith, 2008).

Fourth, herewith these contexts, there are glimpses of how doing policy, or policyresearch is an emotive business, frequently entailing affecting experiences (Laurier and Parr, 2000; Bondi, 2005), and frequently predicated upon empathetic practices (Jupp, 2007a). For instance, Widdowfield (2000, page 201) recognises the capacity of ostensibly dour, objective policy documents to be deeply poignant - "knowing the number of people living in poverty or with cancer", for example - and then suggests that policy-research in such contexts can prove especially moving: for "how much more intense those feelings and that distress, when those numbers become names and those names 'real' people with whom the researcher has face-to-face contact". In so doing, Widdowfield (ibid) owns up to a succession of emotions which have attended her policy-oriented research - distress, sadness, demoralisation, exhaustion, hopelessness, unease, frustration - but which feel somehow 'inappropriate' and 'out of place' in the canon of literature devoted to policyresearch.

\section{Separations of policy and emotion}

Collectively, then, all the above can be read as a twofold truism: (i) policy is always already emotional and affective at heart; (ii) affective intensities are always already latently political. And yet, when it comes to declarations about the present/desirable relationship between social-scientific academe vis-à-vis policy, a peculiar separation even, perhaps, a separatism - is too-often evident. For, in this context, it is not - still not 
- uncommon to witness the domain of 'policy-relevant' social-scientific work being constituted as entirely different to, and mutually excluded from, the domain of work concerned with theoretical and empirical investigations of emotion and affect.

Some recent, ongoing, intra-disciplinary exchanges on 'policy relevance' between Human Geographers (see Ward, 2005) can be read as a microcosm of this sort of separation. For, on one hand, there have a been a range of demands for human geographers to work more assiduously and explicitly "in pursuit of the betterment of society" (Martin, 2001, page 190), through work which is 'useful' and '(policy-)relevant' (Peck, 1999, Dorling and Shaw, 2002). Here, it is not uncommon to see geographers' engagements with contemporary social theory - of which theorisations of emotion/affect are an example par excellence - critiqued as esoteric, "detached from [the] real world" (Hamnett, 1997, page 127), and in thrall to “'sexy' philosophical, linguistic and theoretical issues" (Martin, 2001, page 189). On the other hand, however, there have been gathering demands for human geographers to engage more creatively and philosophically with contemporary social theory (e.g. in relation to emotion/affect). Here, there is sometimes a sense that policy research is dismissible as - basically - dull, lumpen, atheoretical, critically-compromised "low practice" (noted by Pain, 2006, page 252; after Burgess, 2005). These two genres of demand, which refract broader fractures and tensions within Human Geography and other social sciences (Bell, 2007), constitute important prompts/rationales for social-scientific research/practice.

In effect, however, these working assumptions surely precipitate some circumscribed understandings of co(i)mplications of emotion and politics: on one hand via an inclination towards 'policy-relevance', which often distances itself from the ostensible esoteric narcissism of theories of emotion and affect; on the other hand, via an inclination towards contemporary social theory (e.g. around affect and emotion), which often distances itself from policy-oriented modes of research (see Anderson and Smith, 2001). We agree with Anderson and Smith (ibid., also Horton and Kraftl, 2005) that such distanciations produce lacunae in the capacity of social scientists - of whichever inclination - to "both know, and intervene in, the world". 
An example: evaluating a Sure Start Centre

We proceed with a reflection upon one piece of policy-relevant work in one UK policy context: an evaluation of a Sure Start Centre. As the prefatory tears and numbness attest, policy work and emotion were inseparable in this project. We begin with a brief introduction to Sure Start: a major UK-Government programme to improve children's well-being in 'deprived' neighbourhoods. In the next section, we suggest that policy and media discourses, and much extant research, regarding Sure Start have been characterised by a particular apprehension of what matters. This sense also translates into a particular figuring of how policy interventions, in 'deprived' neighbourhoods and elsewhere, should be evaluated. We therefore chart some of the principal concerns of extant Sure Start evaluations, in order to substantiate our concern about the relatively narrow models through which Sure Start provision is both delivered and monitored.

The main body of the paper propounds qualitative data from an evaluation of one Sure Start Centre: our central concern, here, is with the ways in which Centre users articulated how this (policy-constituted, State-provided) facility mattered to them. Our aim is not simply to reiterate the twofold truism: policy is always emotional; emotions are latently political. Rather we consider how, in the wake of this truism, more combinative, openminded encounters between those bodies of social-scientific endeavours conventionally labelled as 'policy-relevant' vis-à-vis 'theoretical' might yield more careful apprehensions of the emotion/effect in policy, and the politics of emotions/effects. 


\section{A policy context: Sure Start}

The UK Government's Sure Start strategy was launched in 1997-99 as a 'landmark' policy intervention to improve the well-being and 'life chances' of children in 'deprived' 3 neighbourhoods (see Glass, 1999). The strategy sought "to work with parents-to-be, parents and children to promote the physical, intellectual and social development of babies and young children - particularly those who are disadvantaged - ... and thereby break the cycle of disadvantage" (Sure Start, 2000, page 1). Four core objectives underpinned this commitment: 'improving [children's] social and emotional development'; 'improving [children's] health'; 'improving children's ability to learn'; 'strengthening families and communities' (Sure Start, 2002). In practice, the policy allocated Central Government funding for the development of locally-managed, multiagency childcare, education and healthcare programmes for the benefit of 0-4-year-olds, and their parents/carers, in the UK's most 'deprived' neighbourhoods. Typically, each programme was physically located in a 'Sure Start Centre'; by 2007 - notwithstanding changes in nomenclature and strategy - around 1250 such Centres were in operation (Sure Start, 2007).

\section{How Sure Start matters 1: extant evaluations}

Two lines of evaluative research are infrastructural to Sure Start; we suggest that this work has been significant in framing a particular concept of the strategy's significance and success. First, the National Evaluation of Sure Start (NESS) is a major, centrallycoordinated, ongoing study of the effectiveness of Sure Start in toto (see Belsky et al., 2007). NESS comprises five substantial sections of evaluative work (Table 1) undertaken by social-scientific/Educational researchers; each section is concerned to gather robust, quantitative evidence of Sure Start's effectiveness. Second, individual Sure Start Centres are statutorily required to undertake 'local evaluations' every 12 months. This work is typically conducted by Sure Start Centre staff, or else commissioned from external consultants or social-scientific/Educational researchers. Sure Start Centres have

\footnotetext{
3 'Deprivation', here, is enumerated at neighbourhood level via the UK Government's Indices of Multiple Deprivation (see ODPM, 2004), which collate indicators regarding seven 'domains of deprivation': income; employment; health; education, skills and training; barriers to housing/services; living environment; crime.
} 
considerable latitude to tailor these evaluations around local needs and contingencies.

Tables $2 \mathrm{a}$ and $2 \mathrm{~b}$ indicate the form and focus of a sample of 344 local evaluations.

Table 1 Research methods used in National Evaluation of Sure Start (NESS) ${ }^{4}$

\section{Impact study}

Initial 90-minute visits by field researchers to homes of c15000 children in 150 Sure Start areas and c2500 children in 50 non-Sure Start (control) areas. Subsequent longitudinal study with visits to homes of children from 100 of the sampled Sure Start areas every 24 months. At each visit, field researchers collect standardised cognitive/observational data, principally via "well-established, psychometrically sound measurement instruments" (NESS, 2005, p.4). Researchers collect data regarding the following variables.

- Demographic and child/family characteristics.

- Child cognitive and language development: standardised testing/scoring using British Abilities Scales.

- Child social and emotional development: closed questions ultimately producing scores regarding child's 'conduct problems', 'hyperactivity', 'prosocial behaviour', 'independence', 'emotional regulation'.

- Child physical health: structured interview regarding child's health history.

- Parenting and family functioning: field observations of 'maternal [sic] responsivity', maternal acceptance; closed questions producing scores regarding 'household chaos', 'home learning environment', 'parent-child conflict', 'parent-child closeness', 'harsh discipline', 'father involvement'.

- Maternal psychological well-being: closed questions producing scores regarding maternal 'malaise' and 'self-esteem'.

- Local context (see below).

Implementation study

- Questionnaire survey for management board of 260 Sure Start local programmes, regarding management/coordination, resource allocation, quantity and type of services provided by local programme.

- Document search/analysis of management/implementation plans of 260 Sure Start local programmes.

- Audit of 26 case study local programmes: structured observation and consultation with staff, management and parents/carers.

- Supplementary thematic evaluations - sharing of practices and case studies regarding issues found to be significant via the implementation study (e.g. buildings in Sure Start programmes, fathers in Sure Start, improving employability of Sure Start users).

\section{Local context analysis}

- Collation of extant UK/regional/subregional Government administrative data regarding Sure Start areas (e.g. indices of multiple deprivation, census data tabulations, work, welfare and pensions data, National Health Service data, employment levels and type, criminal justice system data, school attainments/engagement measures, 'children at risk' data).

- Observations of communities by impact study researchers in sample of streets in area (e.g. structured observation of condition of residences, traffic levels, litter, broken glass, alcohol containers on pavement, perceived personal safety, etc.).

Cost-effectiveness evaluation

- collation of database of quantifiable costs/benefits/targets based on accounts of 260 Sure Start programmes in relation to a sample of core and supplementary provision.

\section{Support to local programmes}

- Collation of local evaluation reports.

- Sharing methods/practice between local programmes.

- Provision of guidance/support for local evaluations.

\footnotetext{
${ }^{4}$ Summarised from the five substantial methodology reports archived on the NESS website: see http://www.ness.bbk.ac.uk/
} 
Table 2a Research methods used in 344 local Sure Start evaluations, 2003-05

\begin{tabular}{|l|l||}
\hline METHOD EMPLOYED & FREQUENCY \\
\hline Interviews - Sure Start staff & 259 \\
\hline Questionnaire survey - Sure Start users & 253 \\
\hline Evaluation of monitoring data & 247 \\
\hline Evaluation of delivery plans & 143 \\
\hline Observations & 120 \\
\hline Consultations with key personnel from other agencies & 111 \\
\hline Focus groups - Sure Start staff & 90 \\
\hline Interviews - Sure Start users & 68 \\
\hline Focus groups - Sure Start users & 56 \\
\hline Questionnaire survey - Sure Start staff & 43 \\
\hline Visual/participatory methods & 28 \\
\hline Consultation with non-users & 18 \\
\hline Consultations with children & 14 \\
\hline
\end{tabular}

Table 2b Primary focus of research in 344 local Sure Start evaluations, 2003-05

\begin{tabular}{||l|l||}
\hline \hline PRIMARY FOCUS & FREQUENCY \\
\hline Measuring user satisfaction & 382 \\
\hline Mapping organisation/roles & 361 \\
\hline Monitoring provision demand/usage & 220 \\
\hline Auditing cost-effectiveness/sustainability & 218 \\
\hline Developing future service strategies & 202 \\
\hline Evaluating outcomes of local provision & 66 \\
\hline
\end{tabular}

Much of this work should be lauded as substantial, exemplary and 'useful' socialscientific research, directly informing Sure Start, nationally or locally. However, consider the ways in which these endeavours have created a particular concept of how Sure Start matters and, therein, have measured its relative 'successes' (or otherwise). First, Sure Start is figured as mattering and effective only insofar as its outcomes measure against certain closed, a priori evaluative criteria: the particular standardized, principally quantitative 'measurement instruments' of NESS; the organisational role-mapping exercises and closed 'user satisfaction' questionnaires of many local evaluations. In practice, for example, the NESS 'impact' study has hitherto produced 'inconclusive' findings about Sure Start's efficacy in terms of the criteria listed in Table 1 (NESS,

\footnotetext{
${ }^{5}$ Derived from an analysis of the 344 local annual evaluation reports archived on the NESS website as of September 2007: see http://www.ness.bbk.ac.uk/annualrpt.asp. This represents a substantial (but not complete) illustrative snapshot of evaluation reports published by English Sure Start Centres between 200305 . The vast majority of these local evaluations employed a range of research methods. Table 2a records every instance of usage of each research method: therefore frequencies sum up to more than 344 . Table $2.3 \mathrm{~b}$ records the primary focus of each of the research methods recorded in Table 2.3a: hence, again, frequencies sum up to more than 344 .
} 
2005). While NESS researchers have carefully explained and auto-critiqued the limitations of these data (NESS, 2005, pages 2-3), their findings have elsewhere been widely repackaged within a pervasive UK media/political discourse which constructs Sure Start as an 'ineffective', 'failing', 'pointless', 'waste of money' 6.

Second, this apprehension of Sure Start's (in)significance and (in)effectiveness has been predicated upon a particular, limited range of encounters with people who use Sure Start provision. That is, Sure Start users have typically been approached as objects of investigation (e.g. via the structured observations and standardised tests which are central to the NESS impact survey) or approached indirectly (e.g. via 'user satisfaction' questionnaires, or via the opinions of staff interviewed in local evaluations). As other have noted, relatively few studies of Sure Start have sought to "[tell] a further part of the story... through qualitative data" (Bagley and Ackerley, 2006, page 717), by “examin[ing] users' experiences... from their own point of view" (Avis et al., 2007, page 204). Third, as such, these extant frames for evaluating Sure Start might be understood as extensions of a tendency - long-noted by feminist social scientists - for policy-oriented social-scientific research to constitute an avoidance or distanciated codification of lived emotions, especially pertaining, for example, to personal, everyday geographies of motherhood (see Holloway, 1998a). Emotions (like attachment and satisfaction) do matter to evaluations like NESS: but only in strictly codified and enumerable languages that delineate relative measures of success - and little more. All of which beckons a question: how else, and how much more, should Sure Start be understood as mattering? And, how else should Sure Start be understood as mattering within the context of the formal evaluative framework for the programme - of which our local evaluation was very much a part?

\footnotetext{
${ }^{6}$ For example, in summer 2005, UK media reportage of NESS (2005) preliminary impact study findings was characterised by front page headlines announcing "[d]oubts over value of $£ 3$ bn Sure Start" (The Guardian 13/9/05) or proclaiming - an oft-used pun, this - "[a] less than Sure Start" (Daily Mail 14/9/05). Similar headlines proliferated over the next eighteen months: thus Sure Start was branded as "failing" (The Times 18/9/05, Daily Mail 23/2/07, The Guardian 10/7/07), as a "total waste of money" and " $£ 1$ bn pound disaster" (Daily Mail 23/2/07).
} 


\section{How Sure Start matters 2: everyday, emotional geographies}

In 2005-06 the authors were part of a team commissioned to conduct a local evaluation of a Sure Start Centre in the English East Midlands. When developing the evaluation with the Centre's Management Board, it was agreed that - in contradistinction to prior evaluations of this and other local Centres - this piece of work should have a strong emphasis upon the voices of users of the Centre, especially their experiences of how the Centre mattered to them. To this end, a key aspect of the project was a programme of indepth interviews with parents/carers who used the centre ${ }^{7}$. In all, interviews were conducted with 150 parents/carers (i.e. more-or-less all users of certain aspects of the Centre over a four-month period ${ }^{8}$ ). Interviews were conducted with groups of 1-4 parents/carers at a time (depending on their preference) around a coffee table in a reasonably quiet side-room of the Centre. It is not our intention in this paper to give a full account of the content and policy-oriented implications of these interviews. Rather, we consider interviewees' responses to just one question: 'how does the Sure Start Centre matter to you?' As a means of reflecting upon the nature of this mattering (see also Jupp, 2007b) our narrative is analytically grouped via three predominant ways in which Sure Start users answered this question: in terms of everyday experiences, emotive experiences, community life, and prompts for individual and collective action. As such, we defer the question of what 'mattering' was to interviewees' modes of articulation: in practice, as will become clear, 'mattering' was used to describe a complex manifold of everyday 'feelings', 'emotions', dispositions, narratives, and individually and socially -articulated bodily intensities (for a fuller account, see Horton and Kraftl, forthcoming).

In short, we suggest that the nature of the kinds of mattering evoked by our interviewees' talk jarred with the tone and assumptions of many chief policy, media and research discourses regarding Sure Start and, as such, demands careful reflection upon co(i)mplications of, on one hand, emotions/affects and, on the other, policy/the political.

\footnotetext{
${ }^{7}$ In total, the evaluation project entailed four major lines of research: (i) in-depth interviews with 150 users of the Sure Start Centre; (ii) shorter interviews with 50 parents/carers who were entitled to use the Centre, but did not; (iii) interviews with staff and stakeholders at the Centre; (iv) qualitative projects with young children using the Centre. Being statutorily required at the time, the project was c from the Sure Start Centre's core funding. As such, the research reported here was effectively infrastructural to this Centre, and thus this national policy intervention. More straightforward summaries of 'policy-relevant' findings/recommendations from the project are available from the authors on request.

${ }^{8}$ All but one of these respondents were female. In the remainder of the paper we therefore refer to respondents as 'mothers'.
} 
How (else) does Sure Start matter?

By way of introduction to our qualitative analysis, Table 3 provides an overview of initial responses to the question: 'how does Sure Start matter to you?' Virtually all interviewees articulated a range of often profound ways in which the Sure Start Centre mattered to them. Note how the top three responses relate to particular 'feelings': feeling less isolated, feeling better, and feeling more supported.

Table 3 How the Sure Start Centre mattered to users ${ }^{9}$

\begin{tabular}{||l|l||}
\hline How the Centre mattered & Frequency \\
\hline 'I feel less isolated' & 43 \\
\hline 'I feel better within myself' & 42 \\
\hline 'I feel more supported' & 36 \\
\hline 'It has changed my life' & 35 \\
\hline 'It helps me with parenting' & 35 \\
\hline 'I feel part of something' & 20 \\
\hline 'It is like a family' & 17 \\
\hline 'My life has direction' & 15 \\
\hline
\end{tabular}

Although the Centre's core work - in terms of Sure Start's aims and evaluative principles - of supporting parenting was commended by $35 / 150$ interviewees, a greater proportion articulated senses of what mattered which differed, somewhat, from the terms of extant national and local evaluations of Sure Start. For many of the users interviewed, Sure start had changed the way they felt: about themselves, about their lives, about their relationships with others, about their communities. In quantitative terms, it emerged that talking about 'feelings' was a key way in which respondents were able to articulate their relationship with the Centre. Indeed, given an opportunity to verbalise their feelings about the Centre, many interviewees felt compelled to recount often detailed, deeplyaffecting stories about how the Centre had come to matter for them. It is these more detailed stories that we consider in the rest of the paper.

\footnotetext{
${ }^{9}$ Note that respondents were able to indicate more than one outcome: hence frequencies do not total 150 .
} 
We suggest that it is important to consider these accounts in greater depth, for three reasons. First, in order to foreground voices and emotions hitherto under-represented (although often hinted at) in many Sure Start evaluations. Second, in order to demonstrate how and why the Centre achieved positive outcomes via manifold, particular, local events and emotional geographies. And third, therefore, to stress - thanks largely to the openness of the parents/carers who participated in our project - what more and what else the Sure Start Centre was able to do in excess of the narrow confines of Sure Start's stated aims and evaluative criteria. In particular, interviewees highlighted how four issues mattered profoundly to them in developing meaningful relationships with the centre, its staff, and other users: everyday matters; emotional matters; community/family matters; and, matters for consideration (and action). Although for the women we interviewed, these issues were related, below we consider each theme in turn, drawing heavily on indicative quotations from the interviews.

\section{Everyday matters}

This paper's contextual sections highlighted a particular emphasis, in extant Sure Start evaluations, upon standardised, quantifiable outcomes/indicators of change that should become apparent amongst parents/carers and children at a local successful centre. In so doing, we suggested that these literatures tend to efface how users of Sure Start would themselves evaluate the success (or otherwise) of their local centre. In studying parenting (and especially mothering), geographers have demonstrated how local, everyday considerations and practices are constitutive of broader concerns such as territorial social justice, class-based inequality, or risk (Holloway, 1998a, 1998b; Pain and Smith, 2008). In addition, they have begun to attend to the processual, performative work involved in learning to become a mother (Madge and O'Connor, 2005). Our study mirrored previous research to some extent (e.g. Holloway, 1998b), as many mothers suggested that the Sure Start Centre provided the respite commonly available from informal baby-sitting networks and formal nurseries. In this context, however, most interviewees belonged to a disadvantaged population who - for financial and personal reasons - could not make use of such resources, and hence they relied on the Centre in order to undertake the most routine of tasks: 
"Coming here is like a huge weight off my mind. I can go to an appointment at the dentist, or go to my English lessons now, because I can trust the people here to look after my children while I am away"

"It gives me two hours in a morning to take a deep breath and relax - I don't have to be constantly watching my child all the time. It gives me time to have a cup of coffee and a chat and sort my head out"

Many mothers commented on how local, particular and ostensibly banal considerations mattered, of themselves, to their level of satisfaction with the Sure Start Centre. For them, the effectiveness of the Sure Start Centre was represented by manifold small achievements, low-key pieces of advice and ostensibly mundane activities.

"I will give you one example. My little lady would never use a cup. Never! But after one day at Sure Start she came home and she used a cup. Like magic!"

"I am always exploring what toys to get and this is an ideal opportunity to listen to the advice that the staff give you... It is very helpful - they will recommend books. For example, if [my child] had a sleeping problem, they will go through and find you a book about it"

"It teaches [my child] about structure...It structures his day - he comes in, plays, has a snack, has lunch, has a snooze. He knows the routine now"

"[My daughter] comes here and she brings what she learns back home with her. And it gives us all sorts of ideas for new things to do. Like we've got her some glue and paint at home now because she came here and really got into it. We would never have bothered with that before"

It transpired that, like many interviewees, the above respondents had found solace, delight and surprise from within some of the smallest achievements (like a child using a cup). More commonly, it seemed, the snippets of advice - about toys, books, routine and suitable activities at home - were particularly valued and singled out for praise. We want to re-iterate the critical importance of such practices - of themselves - for parents/carers who used the Sure Start Centre. In analysing the interview transcripts, the sheer volume of quotations concerning such everyday matters was striking, bearing some testament to their significance for parents/carers. 
Nevertheless, we sought to question why Sure Start users found such significance in small achievements and pieces of advice. As the remaining sections of the paper demonstrate, they mattered for two particular reasons. First, for lone mothers or mothers without family or community support, the centre provided the only source of information and support where even such seemingly banal activities and knowledges could be acquired. For them, taken-for-granted processes of becoming a parent - embodied in informal toys, books, routines and so on - were imbued with greater importance as they were part of the formalised service provided by Sure Start. Second, and therefore, the types of care the centre staff could provide for mothers were unusual in the context of these mothers' lives: everyday knowledges and activities were quite simply the most tangible 'symbol' of the caring relationships they identified at the centre. These basic blocks provided some stability for their lives, in some cases profoundly changing their attitudes to themselves, changing their relationships with their children, and allowing them to enter into caring relationships with other users.

\section{Emotional matters: changing lives}

As we have argued, geographers are beginning to stress the place of emotion in policy and applied research (cf. Bennett, 2004; Kraftl and Horton, 2007). We do not suggest here that local and national evaluations of Sure Start have completely ignored the highly charged and complex emotions that - according to the worker who introduces this paper - characterise life at the centre. For instance, the NESS uses a number of measures (derived from observation and psychological testing) to quantify mothers' attitudes to their children, and children's emotional intelligence. Nevertheless, these measures fulfil a necessarily narrow and technical function, and are not designed to explore the very personal, and very often life-changing, emotional meanings that users attached to the centre. For, quite simply, many interviewees detailed how the Centre had been 'lifechanging'.

"I was very scared. I was thinking 'what is going to happen to me?' The whole time I was in a state - 'what is going to happen? What is going to happen?' I was enclosed somewhere. Coming here, it was like it opened a curtain. It helped me go through it all. It has had a huge impact on me. It's life-changing, it really is" 
"It has made me feel like I can do more with my life than just be a lonely old distressed mum"

"It was just a massive relief. I was suffering from post-natal depression, and [my child] was having to see all these consultants, and things were just going from bad to worse. So it was a huge relief for us all”"

As the previous quotations highlight, many mothers suggested that the transformation in their outlook on life was profound. Their lives 'before' Sure Start had been characterised by diverse outlooks on life - 'distressed', 'bleak', 'scared' and so on. This offers a clear reminder that although they lived in an area characterised by quantifiable socio-economic deprivation, the personal circumstances and particularly the emotional states of these women were very different. Articulated in various ways dependent upon mothers' prior emotional state - 'curtains' opening, the 'lifeline', a 'relief' - attendance at the centre had not only been an emotional (and often difficult) experience in itself, but had enabled respondents to work through their diverse emotional problems. In some cases, Sure Start users related their improved emotional states to further positive changes in their lives.

"It just helps me to be able to function normally. I can get out of bed now and not be scared to go outside"

"It has changed the way I feel within myself. I feel more hopeful, less needy. And now I have got an interview to be a volunteer, and that is amazing”

"To start off with, I couldn't leave the house. Now my life has changed so much. I have new friends and new confidence, all thanks to the people I have met at Sure Start. I go on trips, I do courses, I chat with other mums, I've got maths and English qualifications, I'm thinking of going back to work-all of these things would've seemed impossible before"

"They have done so much for me. It has changed my life. The [staff and other users] helped me write letters to the council and [local M.P] about my accommodation situation, and now I rent a house in the area from the council. They gave me lifts to appointments, and toys and books for the kids while we were in temporary accommodation. I go to courses, and I am aiming to be a parent rep."

Crucially - and returning to points made in the previous section regarding 'everyday' matters - the emotional and everyday support provided by the Centre had encouraged women to raise their aspirations for the future. Furthermore, attendance at the Centre had 
opened up a range of opportunities previously foreclosed by their prior emotional states, their personal circumstances, and the lack of 'everyday' 'know-how' that, as we indicated earlier, so many Sure Start users valued.

"Coming here gives me belief. I do things now that I would never have dreamt of doing this time last year"

"I've learnt so much from coming here - things I'd never even though of before"

"I was living half a life before - now I'm more myself. I've come out of my shell"

Many interviewees explained why the centre was so effective at both dealing with emotional difficulties, and at improving women's outlook, aspirations and opportunities. It transpired that staff at the centre - along with other Sure Start users - worked to create certain atmospheres (cf. Kraftl and Adey, 2008), gesturing towards and adopting certain bodily-emotional dispositions (cf. Laurier and Philo, 2006) which were recognised as 'welcoming' and 'sympathetic' by mothers.

"The staff make you feel welcome from day one. They help you fit in"

"It is a welcoming place, and the staff are always sympathetic. No matter what crap you've been going through, they give you a bit of sympathy and a bit of support"

"When you're here, with people around you, you don't stay down in the dumps for too long!"

These ways of being - no doubt practised and trained - were crucial factors in women's continued use of the centre, and the emotional benefits that, as we have already demonstrated, many mothers clearly obtain from that use. It is perhaps in the constitution and staging of moments such as these that co(i)mplications of 'policy' and 'emotion' are rendered most visible. Elsewhere in our evaluative project, interviews with staff responsible for training 'front line' workers in the Sure Start Centre, revealed some ways in which the above-noted 'welcoming' dispositions and situations were routinely rehearsed:

"One of the first things we get [trainees] to do is to go out with one of our experienced [workers], doing door-to-door [delivery of information about the Centre in neighbouring streets] to get them used to meeting people - to see how our 'pros' do it”' 
"Our job involves getting [trainees] doing various bits of talking with groups [of Sure Start users] and giving them practise at - sort of 'holding hands' and talking through problems"

"We get [trainees] to organise a coffee morning [at the Centre], so they have to take responsibility for making sure everyone feels at home"

Such senses of welcome and sympathy can appear rather banal. Nevertheless, we would emphasise the inter-connectedness of these senses with the more particular forms and practices of caring to which we have already attended - from advice to respite, and from writing letters to finding friends. Indeed, it could be argued that such small practices practising meeting strangers, sitting and talking, making mugs of coffee - were in many ways fundamental to the Sure Start project. Such 'welcoming' practices were explicitly positioned as central to making individuals 'feel at home' within their Sure Start Centre, and thus, ultimately, to sustaining the programme. This feeling 'at home' reportedly led, in turn, to the kinds of emotional shifts documented in this section, which were in their turn central to the situations and changes detailed in the following sections.

\section{Community/'family' matters}

Many mothers emphasised that transformations in their outlook and emotional state were a result of the Sure Start Centre's 'atmosphere'. For them, the centre and its staff provided a surrogate 'family', enabling women to embed themselves in networks of support which hitherto had been missing. These kinds of local networks and parenting cultures - which mothers in other contexts come to rely on (Holloway, 1998b) - were for different reasons seldom available to Sure Start users.

"I being a foreigner don't have relatives or visitors so for a long time I am alone. But I come here and they look after me and visit me. They are like a new part of my family. They give me emotional support, very much. Now people call me on the telephone and say is there anything we can do? How are things?'”

"The staff really make the centre. [The dinner lady] is just fantastic, and [drop-in worker] is very, very good. And I like the fact that some of the staff are more mature and some of them are under 20. It's a good mix. It makes it a good atmosphere - like a family" 
Many women identified that Sure Start's through its 'mix' of workers, constant support (both inside and outside the centre) and welcoming, non-judgmental atmosphere, the centre provided an 'extended family'. Indeed, as the last speaker comments, this extended family seemed even to instigate and connect with previously invisible parenting networks outside the Centre. A minority of Sure Start users reported that this provision had - for them - directly led to a number of positive outcomes. They valorised (and normalised) particular outcomes: a 'normal family'; developing a 'good bond' with one's child; encouraging a child to interact with other children.

"It has helped us to live like a normal family. The support from Sure Start was like having the support from an extended family, which we don't have"

"After I gave birth, I couldn't bear to be on my own with [my child]. Now, thanks to all the help from Sure Start, we have such a good bond. And [my child] has a new circle of friends and is very sociable"

"It has helped him with interacting with children of different ages. He would always be really, really clingy before he came here. Now he comes through the door and he's looking for someone he can play with",

It became apparent that, in reflecting upon their prior emotional states, many Sure Start users had begun to (or had been encouraged to) undertake critical reflections on their prior capabilities as a mother, and upon their child's development in respect of normative expectations (for example having a 'good bond' or 'interacting with children of different ages'). Such expectations are imbued with the language of developmental psychology which - despite our emphasis upon the banal, everyday and emotional - clearly provides a normative moral and social framework through which the Sure Start Centre encourages mothers to learn about (a particular, normatively-framed version of) mothering. Indeed, we discovered that this framework - which implicitly and explicitly refracted the founding ideals of Sure Start, as as manifest in the measures of its major evaluation mechanism (see Table 1) - was internalised by mothers and perpetuated as some of them became carers themselves, whether formally or informally. Hence, again, the co(i)mplication of 'formal', professionalised and evaluative matterings of Sure Start with everyday, emotional matterings: 
"I like the attitude of the staff, and the continuity. There's more mature staff, and they add a sort of homely atmosphere. It is inspiring to see their homeliness and dedication. And the continuity is good. When you see people who start out coming along, and they go and become parent reps and everything, and some even become staff. That is really good"

"It has been very important for us, because we are new to [town], and we didn't know anyone. So Sure Start helped a lot. Now we have little circle of friends, and people we know we can call on if things go wrong"

"It has really turned my whole life upside down - everything has changed for me. I decided that I wanted to do child-minding, and coming to Sure Start in a way really inspired me to think 'you know, I can really do this', and gave me all the info I needed to get cracking"

As the last speaker highlighted, attendance at Sure Start has prompted some women to pursue a career in (child)care. More broadly, though, the centre's 'family' or 'homely' atmosphere has encouraged a wide range of caring relationships, from 'parent reps', to a 'circle of friends' who can be called upon in times of need. Many respondents emphasised the importance of a supportive community of care which was centred around a set of ideals concerning 'family', motherhood and child development.

It is not our intention to critically consider the types of caring taking place at the Centre, rather to signal that the sense of community felt there was for many mothers characterised by caring relationships between mothers and workers. Nevertheless, it was clear that, in addition to providing immediate relief and support for mothers, this particular centre had (perhaps unintentionally) encouraged some women to enter formal caring professions, thereby opening out opportunities previously unavailable to them. The centre and its staff - its community - had enabled women who had previously been reticent, withdrawn and lonely to become able and willing to open themselves up to friendship networks and to actively care for others. Perhaps less optimistically, it seems evident that the particular types of care developed via dense inter-personal relations (cf. Gilligan, 1982) at the centre merely opened out very particular (and limited) lines of opportunity for women, reinforcing traditional gender stereotypes and preserving (child)care as a female-dominated sector. This slight reservation on our part should not colour what in policy circles would be termed the 'value-added' of the centre's provision, especially in terms of mobilising a heavily moralised and even politicised sense of 
community amongst many mothers. We expand upon this point in the final section of our analysis.

\section{Matters for consideration (and action)}

It should be reiterated that many of the mothers consulted were overwhelmingly positive about the Sure Start Centre. Nevertheless, they also criticised some of the centre's failings (Table 4). In line with our other findings, many of the problems they identified were qualitatively different from, but related to, the kinds of criteria on which the centre performed poorly in the NESS. Most significantly, most of the limitations they identified stemmed from organisational matters controlled at a national scale, such as the centre's limited geographical catchment and short opening hours.

Table 4

Users' criticisms of the Sure Start Centre ${ }^{10}$

\begin{tabular}{||l|l||}
\hline \hline Parents'/carers' concerns & Frequency \\
\hline Used by too few local parents/carers & 62 \\
\hline Only available in a limited postcode area & 46 \\
\hline Uncertainty about future of provision & 45 \\
\hline Opening hours too short & 29 \\
\hline Not enough info. about facilities/events & 15 \\
\hline Limited provision for children with SEN & 12 \\
\hline Limited provision for children aged 2+ & 15 \\
\hline Broken toys & 10 \\
\hline
\end{tabular}

We were initially surprised that the most commonly-cited limitation - mentioned by $41 \%$ of respondents - was that the centre was 'used by too few local parents/carers'. Indeed, this was one criticism that we had expected to emerge from evaluations like the NESS, rather than from users. However, understood in the light of many respondents' emotional, moral and social transformations, it appeared that many Sure Start users had adopted a critical and reflective stance about others' (non-)usage of the centre. This critical stance was in some senses a caring one, invoking the many episodes, practices and atmospheres to which we have already attended. Although recognising the many constraints operating upon these women's lives, the Centre, its staff and, increasingly, its users had - by

\footnotetext{
${ }^{10}$ Note that respondents were able to indicate more than one problem: hence frequencies do not total 150 .
} 
providing a nurturing, caring community - raised users' awareness of their own situation, promulgating a sense of belonging and group identity. Their new, politicised awareness combined with their embeddedness in the Centre's nurturing community to create more overt (yet Sure Start-focussed) forms of activism, centered around other mothers' nonusage of the Centre.

"Oh yeah, loads of the mums I know around here don't bother coming, like they think they know what's best for them. But sometimes I feel like going up to them and marching them down here"

"A lot of the younger mums don't come - their attitude is like 'I know better'. It's really frustrating. I feel like going up to them and dragging them in here. Something should be done to help them"

"I know there are people who are ten times worse off than me, but they don't use Sure Start, so I think something needs to be done to get them involved"

The women speaking above represented a feeling that as a direct result of the life changes and emotional investment they had made with Sure Start, they felt able to express a concern that many 'worse off' members of the local community were not using the Centre. In fact, they strove to develop their caring attitude beyond supporting other local parents/carers in order to propose that they want to 'go and grab' non-users.

Other respondents had become acutely aware of the possible closure of the Sure Start Centre (which, at the time of undertaking our research, was a very real possibility as a result of the most recent NESS evaluation). As we detail in another paper (where the four following quotations were first published) the spectre of closure had encouraged similar compulsions for activism, centred around a group identity and sense of collective support (Horton and Kraftl, forthcoming):

"I haven't had anything to do with that side of things, but if there was a big issue, I think most of the mums here would be up for it. We stick together like that"

"We look out for each other, so if anything bad happened I think we'd give someone a right earful!... If they took this away, a lot of people would be up in arms!" 
"I haven't really got the time to be a parent rep[resentative], but if it was something serious, like if they started seriously talking about closing this place down, I think we'd stand up for ourselves"

Respondents offered different levels of commitment to the Centre but stressed that a certain kind of politically awareness had been awakened amongst users. Central to this awareness was a desire to 'give something back' to the Centre and its staff and to preserve a resource that held so much emotional meaning for them. We would be wary of overly praising such 'single-issue' politics, and we would seek to clarify that we are unsure about how such awareness might translate into other forms of activism, community or otherwise. Rather, we seek to stress the intimate, informal and complex relationship between what clearly mattered to parents/carers using Sure Start (emotional stability, community support, 'everyday' advice) and the unanticipated emergence of albeit localised forms of political commitment, centred around care. Furthermore, it is worth remembering how much the Sure Start Centre, and the highly involved performances of becoming a parent/carer at the Centre dominated the lives of our interviewees.

\section{Conclusions: what matters most?}

Our aim in this paper has been to expand upon the ways in which we (academics, policymakers, publics) can understand how institutions like Sure Start matter. We have identified - through interviews with 150 users of one Sure Start Centre - how localised practices, atmospheres and knowledges both complement and very often exceed the directives of this UK-wide service. In allowing users to voice their experiences and concerns, we reported on some of the same criteria that national-scale, quantitative evaluations such as the NESS use, and have similarly expressed some of the shortcomings of a service which is, ostensibly given the findings of many extant evaluations, 'failing'. However, guided by users' experiences of one particular Sure Start Centre, we have sought to demonstrate that an attentiveness to other concerns -

principally centred around everyday, emotional geographies and the particular kinds of care-focussed moralities and politics fostered there - allows an alternative, largely positive image of success to emerge. Our paper thus demonstrates some particular 
co(i)mplications of 'emotion' and 'policy' which, in many ways, undermines the largely negative picture of our case study Centre painted by NESS.

Whilst the contrast is striking, we want to stress in closing that co(i)mplications of 'policy' and 'emotion' should not simply be mobilised to compare the national/formal with the local/informal. In our study, Sure Start users particularly valorised (and came to normalise) what to many readers might seem banal pieces of advice about books, toys and routines, whilst they valued the principles of 'welcome' and 'family' that Centre staff both embodied and embedded as part of the Centre's atmosphere. They stressed that in many ways - but specifically their emotional mindset, aspirations and political mindedness - their experience of this Sure Start Centre had changed their lives for the better: and not especially in ways intended, anticipated or registered by the aims, infrastructure and many formal evaluative mechanisms of Sure Start itself. Yet it is important to remember that many of the kinds of care, of emotional work, of detailed, banal strategies for coping, are directly related to the kinds of (formal, professionalised) provision that Sure Start workers are trained to give. Some of the emotional changes recalled in this paper (for instance in a mother's relationship with their child) are key aims for Sure Start, even if they are couched in the language of developmental psychology (Table 1). Similarly, the aim of fostering a community of mothers is not at all alien to the stated objectives of the programme, or to the UK Government's longstanding interest in social inclusion (however derided this commitment has become in certain critical circles). Rather, our study demonstrates how mothers simply valued very particular elements of those formal activities - in effect, in our interviews, they re-framed the work done by the Centre in their own terms, giving them life, fleshing them out, recalling why they mattered to their everyday lives and emotional well-being. Furthermore, though, mothers took their discussions elsewhere: the point still holds that Sure Start mattered in so many more (banal, emotional, even political) ways than the programme co-ordinators could predict. Perhaps this signals the success of a service that is flexible enough to allow local concerns and issues to be addressed. Perhaps - bearing in mind that much of this Sure Start's Centre's 'community' comes from its threatened closure - this paper is testament to the ways in which Centre workers and users have worked with the stated aims of the programme to make something more of the Centre - 
something that was not recognised by NESS. Either way, it is fair to say that 'formal' policy and 'informal' doing are not so distant from one another - they simply involve different articulations and/or practices of 'policy' and 'emotion'.

The Sure Start Centre evidently constituted an iteratively-defined space where women could negotiate their ideals, aspirations, emotions and performances about motherhood (cf. Madge and O'Connor, 2005), and gain an albeit narrowly-defined and normative sense of their group identity and political agency as 'Sure Start mums'. If we recognise that places like this one Sure Start Centre are perhaps not that unique - and that they constitute spaces where emotional meanings, informal and formal ethics of caring, and forms of political activism can emerge - then perhaps there may be scope for reconsidering 'what (else) matters' as services such as Sure Start are created, evaluated and, potentially, shut down. If we do, then we may take (more) seriously the politics, moralities and solidarities that matter.

To return, finally, to our opening discussions, we wonder: how to apprehend articulations of 'emotion' and 'policy' in the wake of the kinds of stories re-presented herein (our tears in a car; our interviewees' experience of 'sorting their head out'; the Centre staff members' sympathy 'no matter what crap you've been going through')? Or, to frame it differently: in the wake of such stories, what makes a 'good' evaluation? Part of the difficulty of addressing such questions is the ease with which - within the context of a subdisciplinary life and canon - one can fall back upon a conventional array of positions intricately wedded to the 'separations' sketched at this paper's outset. Certainly, when reflecting upon the project detailed in this paper, the readings which most readily suggest themselves fall into this trap. For the material re-presented in the preceding sections could be read as manifestly evidencing the deficiencies of extensive, quantitative or policy-relevant projects versus in-depth research attuned to the everyday, emotional geographies. Conversely, it might be read in entirely the opposite way (to be honest, we would direct readers to NESS, rather than our own work, for exemplary, densely-detailed, effectively-definitive evaluative social-scientific research regarding Sure Start).

However, it is our contention that the kinds of events and geographies evoked in this paper can matter with an intensity which can, sometimes, make such positions feel 
irrelevant (see postscript) and which should demand habitually-oppositional modes of social-scientific thinking and working to be brought into closer, and more generous, interrelation. At the risk of resorting to truisms, this might take three related forms. First, policy-led social-scientific research projects might more often incorporate in-depth research or creative practices attuned to quotidian, emotional geographies. Second, avantgarde theorisations of emotion and affect might be directed more readily towards contexts and matters of contemporary social-political concern and inequality. Third, these two arcs might more proactively seek opportunities to draw one-another into efficacious collaborative practices which, whilst drawing together different senses of what 'matters', might constitute - basically - an openness to being upset by the world...

\section{Postscript}

Three years on, whilst trying to write an argument about articulations of 'policy' and 'research', I find myself staring blankly at the PC monitor thinking back to that story from the Sure Start Centre, and being in the car with my co-researcher in tears. I rub my tired eyes, make a cup of tea, go for a walk and try to shake off the memory. 


\section{Acknowledgements}

Thanks are due to Chris Durkin, Sue Kennedy and Ruchira Leisten, who worked on the evaluative project reported in this paper. We also gratefully acknowledge the generous support given to the project by the staff and users of the Sure Start Centre. We also thank three anonymous referees for their helpful and supportive comments on an earlier version of this paper.

\section{References}

Amin A, Thrift N, 2002 Cities: reimagining the urban (Polity, Cambridge).

Anderson B, Harrison P, 2006, "Questioning affect and emotion" Area 28 333-335.

Anderson B, Holden A, 2008, "Affective urbanism and the event of hope" Space and Culture 11142-159.

Anderson K, Smith S, 2001, "Emotional geographies" Transactions of the Institute of British Geographers 26 7-10.

Avis M, Bulman D, Leighton P, 2007, "Factors affecting participation in Sure Start programmes: a qualitative investigation of parents" views" Health and Social Care in the Community 15 203-211.

Bagley C, Ackerley C, Rattray J, 2004, "Social exclusion, Sure Start and organisational social capital" Journal of Education Policy 19 595-607.

Bell D, 2007 "Fade to grey: some reflections on policy and mundanity" Environment and Planning A 39 541-554.

Belsky J, Barnes J, Meluish, E. 2007 The National Evaluation of Sure Start (The Policy Press, Bristol).

Bennett K, 2004, "Emotionally intelligent research" Area 36 414-422

Bessant J, 2008, "The sociology of policy-making in the modern state" Journal of Sociology 44 283-300.

Bondi L, 2005, "The place of emotions in research: from partitioning emotion and reason to the emotional dynamics of research relationships", in Emotional Geographies Eds J Davidson, L Bondi, M Smith (Ashgate, Aldershot) pp 231-246.

Bondi L, Davidson J, Smith M, 2005, "Introduction: geography's 'emotional turn"', in Emotional Geographies Eds J Davidson, L Bondi, M Smith (Ashgate, Aldershot) pp 1-16.

Brown G, 2007, "Mutinous eruptions: autonomous spaces of radical queer activism" Environment and Planning A 39 2685-2698.

Brown G, Pickerill J, forthcoming, Editorial introduction: activism and emotional sustainability", submitted to special issue of Emotion, Space and Society.

Burgess J, 2005, 'Follow the argument where it leads: some personal reflections on 'policy-relevant' research" Transactions of the Institute of British Geographers 30 273-81.

Chouinard V, 1997, "Making space for disabling differences: challenging ableist geographies" Environment and Planning D 17 379-387.

Cloke P, May J, Johnsen S, 2008, "Performativity and affect in the homeless city" Environment and Planning D 26 241-263.

Dewsbury JD, 2007, "Unthinking subjects: Alain Badiou and the event of thought in thinking politics" Transactions of the Institute of British Geographers 32 443-59.

Dorling D, Shaw M, 2002, "Geographies of the agenda: public policy, the discipline and its (re) "turns"” Progress in Human Geography 26 629-646.

Glass N, 1999, "Sure Start: the development of an early intervention programme for young children in the United Kingdom" Children and Society 13 257-264.

Hamnett C, 1997, “The sleep of reason?" Environment and Planning D: Society and Space 15 127-128.

Holloway S, 1998a, "'She lets me go out once a week': mothers' strategies for obtaining 'personal' time and space" Area 30 321-330.

Holloway S, 1998b, "Local childcare cultures: moral geographies of mothering and the social organisation of pre-school education" Gender, Place and Culture 5 29-53.

Horton J, Kraftl P, 2005, "Editorial. For more-than-usefulness: six overlapping points about Children's Geographies" Children's Geographies 3 131-143.

Horton J, Kraftl P, forthcoming, "Small acts, kind words and 'not too much fuss': implicit activisms", submitted to special issue of Emotion, Space and Society. 
Hubbard P, 2005, “'Inappropriate and incongruous': opposition to asylum centres in the English countryside" Journal of Rural Studies 21 3-17.

Jupp E, 2007a, "Participation, local knowledge and empowerment: researching public space with young people" Environment and Planning A 39 2832-2844.

Jupp E. 2007b. "The feeling of participation: everyday spaces and urban change" Geoforum 39 331-343.

Kraftl P, Adey P, 2008, "Architecture/affect/inhabitation: geographies of being-in buildings" Annals of the Association of American Geographers 98 213-231.

Kraftl P, Horton J, 2007, “"The health event': everyday, affective politics of participation” Geoforum 38 1012-1027.

Laurier E, Parr H, 2000, "Emotions and interviewing in health and disability research" Ethics, Place and Environment 3 98-102.

Laurier E, Philo C, 2006, "Cold shoulders and napkins handed: gestures of responsibility” Transactions of the Institute of British Geographers 31 179-192.

Madge C, O'Connor H, 2005, "Mothers in the making? Exploring notations of liminality in hybrid cyber/space" Transactions of the Institute of British Geographers 30 83-97.

Martin R, 2001, "Geography and public policy: the case of the missing agenda" Progress in Human Geography 25 189-210.

NESS [National Evaluation of Sure Start], 2005 National Evaluation Report: early impacts of Sure Start Local Programmes on children and families (DfES Sure Start Unit, London).

ODPM [Office of the Deputy Prime Minister], 2004 The English Indices of Deprivation 2004: summary (revised) (ODPM, London).

Pain R, 2001, "Crime, space and inequality”, in Introducing Social Geographies Eds R Pain, M Barke, D Fuller, J Gough, R MacFarlane, G Mowl (Arnold, London) pp 231-253.

Pain R, 2006, "Social geography: seven deadly myths in policy research" Progress in Human Geography 30 250-59.

Pain R, Smith S, 2008 Fear: critical geopolitics and everyday life (Ashgate, Aldershot).

Peck J, 1999 "Editorial: grey geography?" Transactions of the Institute of British Geographers 24 131-135.

Skelton T, Valentine G, 2003, "Political participation, political action and political identities: young d/deaf people's perspectives" Space and Polity 7 117-134.

Smith F, Jamison J, Dwyer C, 2008, "Work and wonder at the weekend: on emotions in feminist geographical praxis" Gender, Place and Culture 15 533-545.

Smith M, 2005, "On 'being' moved by nature: geography, emotion and environmental ethics", in Emotional Geographies Eds J Davidson, L Bondi, M Smith (Ashgate, Aldershot) pp 217-230.

Sure Start, 2000 What is Sure Start? (DfES Sure Start Unit, London).

Sure Start, 2002 Sure Start: a guide for Sixth Wave programmes (DfES Sure Start Unit, London).

Sure Start, 2007 Sure Start Centres pass the million mark. DfES Sure Start Unit press release, 11/4/07.

Thrift N, 2004, "Intensities of feeling: towards a spatial politics of affect" Geografiska Annaler Series B 86 57-78.

Thrift N, 2008 "Turbulent passions: towards an understanding of the affective spaces of political performance", In Non-representational theory: space, politics, affect Ed N Thrift (Routledge, London) pp 220-254.

Valentine G, 2008, "Living with difference: reflections on geographies of encounter" Progress in Human Geography 32 323-37.

Ward K, 2005, "Geography and public policy: a recent history of "policy relevance"" Progress in Human Geography 29 310-319.

Widdowfield R, 2000, "The place of emotions in academic research" Area 32 199-208.

Williams S, 2001 Emotion and Social Theory (SAGE, London). 